\title{
Problem-Based Learning in Online Settings during COVID-19
}

\author{
Anna Caroni \\ University of Applied Sciences and Arts Northwestern Switzerland \\ anna.caroni@fhnw.ch
}

\author{
Anna Nikoulina \\ University of Applied Sciences and Arts Northwestern Switzerland \\ anya.nikoulina@fhnw.ch
}

\begin{abstract}
Purpose: Problem-based learning (PBL) provides an appropriate instructional strategy to engage a student in active learning, enhance student interest, improve retention, and promote problem-solving and critical thinking skills. This study aims to report on student and faculty experiences in a problem-based learning course consisting of a preparation phase and a reporting phase during the COVID-19 lockdown and present potential implications for online PBL course design.
\end{abstract}

Study design/methodology/approach: A survey was conducted to compare the two instructional PBL settings, i.e. face-to-face and online. Descriptive statistics as well as a general inductive approach for analysing the qualitative data are used to evaluate the results of the survey.

Findings: The results show that students appreciated the new small group discussion format in the online PBL course over the whole class discussion in the face-to-face setting and that an online PBL course can help students integrate knowledge and promote the deep learning approach.

Originality/value: The study contributes to PBL research by examining student and faculty experiences in a case-based PBL course. A new instructional online PBL course design is presented, with the main change in the reporting phase. The study shows that the shift from a physical to an online setting has no detectable negative impact on the ability of students to achieve set learning goals if the PBL approach is slightly modified.

Keywords: Problem-based learning, online settings, COVID-19

\section{Introduction}

Problem-based learning (PBL) is a well-established approach to teaching and learning in business education, but also other fields such as engineering, medicine, and psychology (Hmelo, 1998; De Graaf \& Kolmos, 2003; Reynolds, 1997; Smith, 2005). This instructional strategy, which includes case-based learning, aims to engage students in active learning, enhance interest, improve retention, and promote problem-solving and critical thinking skills (Prince, 2004; Savin-Baden, 2007). The focus of PBL is on the integration of knowledge and the facilitation of deep learning. By working with case studies, students rely on their behavioural, emotional, and cognitive skills to understand literature, draw on previous knowledge structures, and find solutions to real problems. As a result, students acquire a more in-depth understanding of the material and can reflect on the solutions while gaining cognitive and independent-learning skills (McLellan, 2004; Dolmans, Loyens, Marcq, and Gijbels, 2016; Beattie, Collins, and Mcinnes, 1997; Furlong et al., 2003; Kahu, 2013).

In designing the undergraduate business management course, we applied the classic PBL approach consisting of a preparation phase with self-study and preparatory assignment and a reporting phase in a face-to-face group setting where a lecturer facilitated the discussion. In the preparation phase, knowledge was discussed, while in the reporting phase knowledge was integrated into a face-to-face group setting (Kirschner \& Van Merriënboer, 2008). The course also included scaffolds in the form of carefully designed problems and questions, which helped 
to guide students during the preparation phase and the reporting phase (Ertmer \& Glazewski, 2019).

Before COVID-19 the course was taught physically in class settings of 15-25 students. However, due to government-imposed restrictions and university closure over a considerable amount of time, the course had to be converted to an online setting. This required faculty to adjust the course design. While the preparation phase of the course remained mostly unchanged, major changes were needed to the reporting phase.

In converting the course from a physical to an online setting, lecturers had concerns as to what impact this shift would have on students' ability to achieve the learning objectives of the course. For example, earlier studies point out that online settings are less appropriate for flexible “adjusting as you go" approaches (Savin-Baden, 2007). In addition, to develop critical thinking and problem-solving skills, PBL requires a high degree of collaboration and interactivity for knowledge acquisition, which is more difficult to achieve in the online setting. Faculty's role also becomes more visible as online settings require clear communication of expectations and deliverables, as otherwise students may get confused and lose motivation with online and distance learning (Bocchi, Eastman, and Swift, 2004; Dykman \& Davis, 2008). Furthermore, lecturers and students had little experience with online teaching and learning before the lockdown.

At the end of the semester, we asked students to complete a survey, where we asked them about their overall experience with the PBL course, and also asked for specific feedback on the online instruction PBL design. Similarly, faculty feedback was also collected and evaluated. This study aims to report on student and faculty experiences concerning a problem-based learning course during the COVID-19 lockdown and to present potential implications for online PBL course design.

\section{Literature Review}

Problem-based approaches to learning have a long history. They are one of many instructional approaches that situate learning in a meaningful task, such as case-based instruction and projectbased learning (Hmelo-Silver, 2004). PBL can be defined as a student-centred approach to learning, which is organised around problems, and which takes place in small groups where the lecturer acts as a facilitator (Chung \& Chow, 2004).

PBL is focused, experiential learning organized around the investigation, explanation, and resolution of meaningful problems (Barrows, 2000). The problem is the starting point of the learning process. The type of problem is dependent on the specific organisation, curriculum, and setting. Usually, problems are based on real-life examples or challenges, which have been selected and edited to meet educational objectives and criteria (De Graaf \& Kolmos, 2003). Business and management problems tend to cover strategy, finance, innovation, marketing, and current topics such as digitalization and sustainability. The problems have to be carefully selected to fit the students' background, expectations, and interests. If these are fulfilled, students are more motivated and work much harder with the PBL models rather than with traditional teaching methods (Wijnia, Loyens \& Derous, 2011). There is a relationship between the teaching method and the depth and complexity of the learning, as the student may be expected to reach a level of analytically complex comprehension through problem-based work that would not be possible in any other setting (Hung, Jonassen, and Liu 2008; Savin-Baden, 2007).

In PBL, students work in small collaborative groups and learn what they need to know to solve a problem. Notably, the teacher acts as a facilitator to guide student learning through the learning cycle in conventional classes. All the approaches emphasize that learners are actively 
constructing knowledge in collaborative groups. Furthermore, the roles of the student and lecturer are transformed. Students need to take a more active approach to learn, while the lecturer is no longer considered to be the main repository of knowledge and instead becomes the facilitator of collaborative learning (Kolmos et al., 2008). The lecturer helps to guide the learning process through open-ended questioning designed to get students to make their thinking visible and to keep all the students involved in the group process (Hmelo-Silver 2004; Koschmann, Myers, Feltovich, and Barrows, 1994). The PBL facilitator (a) guides the development of higher-order thinking skills by encouraging students to justify their thinking and (b) externalizes self-reflection by directing appropriate questions to individuals (Kolmos et al., 2008).

The PBL approach to teaching and learning has a significant number of positive impacts on students. For example, Hung et al. (2008) find that PBL learning has a positive impact on the abilities of students to apply knowledge and transfer problem-solving skills to real-world professional and personal situations. Other researchers find a difference in students' abilities to recall knowledge. For example, while studies report no difference in short-term recall and retention between PBL and traditional students, long-term recall and retention are better in PBL students (Norman \& Schmidt, 1992; Dochy, Segers, van den Bossche, and Gijbels, 2003). In addition, Hmelo (1998) and Hmelo, Holton, and Kolodner (2000) observe that students' problem-solving skills and critical thinking processes changed qualitatively over time. Since the ultimate goal of PBL is to educate students to be independent, self-directed and life-long learners, it is important not to neglect reasoning and metacognitive processes. For example, students learn how to think and learn independently by completing a self-study, and by observing the lecturer's problem-solving and critical thinking processes (Hung et al., 2008). Graduates of PBL courses rated themselves better prepared professionally than their counterparts in terms of interpersonal skills, cooperation skills, problem-solving skills, selfdirected learning, information gathering and professional skills such as running meetings and the ability to plan the workload efficiently (Schmidt \& van der Molen, 2001; Schmidt, Vermeulen, and van der Molen, 2006).

Online problem-based learning captures the vast array of ways in which PBL can be taught synchronously and asynchronously, on campus or at a distance. For example, students can learn through web-based materials, including text, simulations, videos, demonstrations and resources, chat, whiteboards and environments that have been purpose-built for PBL (SavinBaden, 2007). In general, moving courses online requires more than the digitalisation of faceto-face classes; teaching and learning online require a different approach. The online PBL must maintain student focus, which fosters their interest, curiosity, and deep learning (Hill et al. 2004; Keeton, 2004).

Thus, combining PBL and the online setting is complex and poses several challenges (SavinBaden, 2007). First, there is a risk of interfering with some of the original aims of PBL since some forms of online PBL tend to focus on solving narrowly defined problems that then fail to encourage students to develop problem-solving, cognitive thinking and independent learning skills. It is important that cases present complex problems, which require intensive discussions, which facilitate the acquisition of higher cognitive skills (Şendağ \& Odabaşı, 2009). Secondly, online settings may reduce the impact of learning in teams since face-to-face settings allow for more natural collaboration than in online environments. Typically, PBL teams comprise 8-10 participants, while final discussions take place in groups of 25-30 students. It is expected that students work collaboratively to solve problems in PBL, which can be done in real-time or asynchronously (Savin-Baden, 2007). PBL also requires a transition from teaching to learning and from teacher-centred approaches to learner-centred approaches. Online settings can support PBL as they can facilitate personalized learning regardless of time and space boundaries, 
making learning more flexible and attractive (Şendağ \& Odabaşı, 2009). It is, therefore, according to An and Reigeluth (2008) important that the online PBL sustains collaboration and interactive group discussions. If this is given, they conclude that a PBL course can have a unique motivating effect. The success of online PBL requires in addition that the role of the lecturer as a facilitator, guide and discussion moderator be clearly explained at the beginning of the process (Donnelly, 2006).

\section{Method}

A survey was conducted to compare the two instructional PBL settings, i.e. face-to-face and online. Both settings were used in the same case-based course allowing for comparability by the students and involved faculty. The course took place in the spring semester of 2020, in the last semester of the student's bachelor's degree program in business administration. The course was taught in German and English. Two classes in German each consisting of 15 students, and two classes in English consisting of 20 and once 21 students attended the course. Six different case studies were carefully selected by the lecturers and purchased through the Case Centre. The topics covered included marketing, finance, strategy, human resource and organizational behaviour, management, and sustainability. Due to the COVID-19 lockdown, the course had to be converted to an online setting after the first face-to-face case discussion. The survey was completed in full by 38 students of both degree programmes. Descriptive statistic as well as a general inductive approach for analysing the qualitative data are used to evaluate the results of the survey. In addition, the faculty involved in the course shared the experience in a post semester workshop and an internal experience report.

\section{Instructional face-to-face PBL Setting}

We applied a classic PBL approach to the course - a preparation phase with self-study and preparatory assignment and a reporting phase in a face-to-face group setting (Kirschner \& Van Merriënboer, 2008). The same structure was used for all six case studies. The main learning objective of the course was that students actively apply, connect, and integrate the knowledge they have acquired during their core business administration courses, such as marketing, finance, and human resource management. Furthermore, additional themes were also included such as sustainability and digitalization. The course aimed to strengthen students' critical thinking, problem-solving, independent learning, and team skills.

In the preparation phase, after examining the respective case individually to gain a deeper understanding of the problem, students were able to prepare for the group discussion in selfselected teams of three to four students. They worked in the same teams throughout the entire course. Scaffolds, such as carefully designed problems and questions, were used to guide and motivate students (Ertmer \& Glazewski, 2019). For example, students were asked to carry out a comprehensive analysis of the case by applying models and frameworks acquired in previous semesters and to come up with a set of recommendations for a concrete business problem. As a final step, teams were asked to submit a five-page written assignment outlining their preparatory work, analysis, and recommendations via the learning management system MOODLE.

The reporting phase included face-to-face discussions facilitated by the lecturer. The discussions took place in the plenary group setting. Alternative decisions or recommendations for implementation were discussed and examined in depth allowing the students to build new knowledge. The advantages and disadvantages of the alternatives had to be critically weighed up, and all positions in the discussion had to be supported with clear argumentation and evidence. The face-to-face plenary discussion lasted for two hours. 
The role of the lecturer was clearly defined and explained at the beginning of the course as that of a facilitator, guide, and discussion moderator (Donnelly, 2006). A second, supporting instructor was part of each plenary discussion. His or her task was to evaluate the quality of students' contributions to the discussions. A different lecturer and expert in his or her field moderated each of the six case studies.

The grading policy specified that the preparatory assignment for each case accounts for $30 \%$ and the grade from the plenary discussion accounts for $70 \%$ of the final grade for each case. The grade for each case was communicated within a week after the case discussion. The five highest-graded cases were consolidated into an overall grade at the end of the course.

\section{Instructional online PBL Setting}

In the online PBL setting, the grading policy, as well as the preparation phases, remained unchanged. However, the reporting phase, which was planned as a face-to-face setting, had to be changed to an online setting. Since a plenary discussion with 15 to 21 students is more complex to facilitate in an online setting, the class was divided into smaller groups of five to six students to facilitate interactivity and to enable all students to contribute in the online setting. In turn, we expected to get a higher quality discussion among the participants. Groups for the interactive discussion consisted of only one or two members from the different preparation groups. Furthermore, the discussion time per discussion group was reduced to 45 minutes.

The role of the lecturer responsible for the case expanded through the online setting. Besides the role of the facilitator, the lecturer also became the "master of ceremony", communicating the start and end times of the discussion times, and informing students of the discussion procedure. This was in order to ensure that students knew exactly what was expected of them during the discussion, including how to interact in the online setting, which was still new to them. The lecturer had to moderate the discussion more actively to keep the discussion going (Bocchi et al., 2004; Dykman \& Davis, 2008).

\section{Results}

Regarding learning success, $76 \%$ of the students stated that the learning success was "rather high" or "high" and $60.5 \%$ indicated that they would like to have more PBL in the degree programmes $(n=23)$. Among these students, $70 \%(n=16)$ wished that casework would then be assessed. The main learning objective was that students actively apply, connect, and integrate the knowledge. In the inductive qualitative analysis of the open question in the survey, the category integration of knowledge was created (see Table 1). This makes up $14.29 \%$ of all answers. The students stated that they appreciated being able to apply the knowledge they had acquired in the previous modules (McLellan, 2004; Dolmans et al., 2016). The experience of the lecturers shows that PBL can promote the students' ability in Bloom's taxonomy categories "apply, analyse, evaluate" and can clearly foster problem-solving skills as well as critical thinking skills (Savin-Baden, 2007).

$89 \%$ of respondents indicated in the survey that they found the variety and selection of cases enriching. In the inductive qualitative analysis, the category chosen cases were created (see Table 1). This accounts for $16.33 \%$ of all comments in the open question. The students appreciated that the cases handled current topics and had a strong practical orientation. Students also valued the variety of topics and fields in the case selection. The faculty highlighted that complex and practical oriented problems are key to enable an interactive and intensive discussion which reveal the higher cognitive abilities of the students (Şendağ \& Odabaşı, 2009).

The grading policy provided a timely evaluation. Of the 6 cases to be completed, only the 5 best graded counted towards the overall grade. The lecturers wanted to know whether this 
would reduce motivation towards the end of the course. $97 \%$ of the students indicated in the closed question that they appreciated the timely assessment and 87\% reported that it did not reduce their motivation towards the end of the semester. The grading policy did not provide detailed feedback on each grade. Students expressed the wish that faculty should provide more detailed feedback. The category grading policy made up $22.45 \%$ in the qualitative analysis. $72.73 \%$ of the comments in this category are assigned to the sub-category "feedback". In addition, regarding constructive alignment, the faculty realized that the preparatory assignment should account for more. This is in line with students' statements in the sub-category “weighting” (27.27\%).

Table 1: Categories formed in qualitative analysis (own development, 2020)

\begin{tabular}{|c|c|c|}
\hline Category (\%) & Sub-category (\% in category) & Example \\
\hline \multirow[t]{3}{*}{$\begin{array}{l}\text { Online PBL Setting } \\
(34.69 \%)\end{array}$} & Flexibility/ Efficiency (23.53\%) & $\begin{array}{l}\text { The } 45 \text { minutes were more efficient in my } \\
\text { opinion. } \\
\text { Discussions on Webex are much better and more } \\
\text { pleasant than on-site. }\end{array}$ \\
\hline & $\begin{array}{l}\text { Interactivity } \\
(17.65 \%)\end{array}$ & $\begin{array}{l}\text { I thought the small groups were better because } \\
\text { the discussions were more intensive. }\end{array}$ \\
\hline & $\begin{array}{l}\text { Small discussion groups } \\
(58.82 \%)\end{array}$ & $\begin{array}{l}\text { The smaller groups have improved the quality of } \\
\text { the discussions. }\end{array}$ \\
\hline \multirow[t]{2}{*}{$\begin{array}{l}\text { Grading Policy } \\
(22.45 \%)\end{array}$} & $\begin{array}{l}\text { Weighting } \\
(27.27 \%)\end{array}$ & $\begin{array}{l}\text { In general, the paper should be rated more than } \\
30 \% \text { in my opinion. }\end{array}$ \\
\hline & $\begin{array}{l}\text { Feedback } \\
(72.73 \%)\end{array}$ & $\begin{array}{l}\text { More detailed feedback would have been } \\
\text { important to me instead of just receiving the } \\
\text { grade. }\end{array}$ \\
\hline \multirow[t]{2}{*}{$\begin{array}{l}\text { Chosen Cases } \\
(16.33 \%)\end{array}$} & $\begin{array}{l}\text { Practical orientation } \\
(37.50 \%)\end{array}$ & $\begin{array}{l}\text { I really enjoyed working on all the cases } \\
\text { (especially very practically related). }\end{array}$ \\
\hline & $\begin{array}{l}\text { Variety } \\
(62.50 \%)\end{array}$ & $\begin{array}{l}\text { The cases were exciting, and it was nice to be } \\
\text { able to pick up things from different modules. }\end{array}$ \\
\hline \multirow[t]{2}{*}{$\begin{array}{l}\text { Integration of } \\
\text { knowledge } \\
(14.29 \%)\end{array}$} & $\begin{array}{l}\text { Applied what learnt } \\
(57.14 \%)\end{array}$ & $\begin{array}{l}\text { In the module, I was able for the first time to } \\
\text { properly recognize the connections between the } \\
\text { methods and models learned in the degree } \\
\text { programme. }\end{array}$ \\
\hline & $\begin{array}{l}\text { Learnt a lot in general } \\
(42.86 \%)\end{array}$ & $\begin{array}{l}\text { I have learned a lot. } \\
\text { I was able to gain even more knowledge about } \\
\text { the case. }\end{array}$ \\
\hline \multirow[t]{2}{*}{$\begin{array}{l}\text { Negative experiences } \\
(12.24 \%)\end{array}$} & $\begin{array}{l}\text { Rhetoric } \\
(16.67 \%)\end{array}$ & $\begin{array}{l}\text { At the same time, the eloquent ones with little } \\
\text { preparation got good marks. }\end{array}$ \\
\hline & $\begin{array}{l}\text { Time-consuming } \\
(83.33 \%)\end{array}$ & $\begin{array}{l}\text { Working out the case studies sometimes took a } \\
\text { lot of time, so } 5 \text { cases would be optimal. }\end{array}$ \\
\hline
\end{tabular}

The reporting phase contained the main difference between the two instructional PBL settings. $89 \%$ of the students indicated in the survey that they appreciated the small group discussion format in the online PBL setting more than the whole class discussion in the face-to-face setting. This result was also clearly visible through the qualitative analysis. The category online PBL setting, which contains statements on the preference of this setting, made up 34.69\%. Most of the students highlighted that they preferred the small discussion groups (58.82\%). The reasons are the improved discussion quality. Students felt that their chances of making an individual contribution were higher, that the motivation increased, and they gained more knowledge. The preference for smaller discussion groups is consistent with faculty experience. Students know that their contributions will be evaluated. Therefore, their focus is on their own contribution. The experience of the lecturers shows that the students are more likely to rely on what their fellow students have said in small groups which increases the discussion quality. The subdivision of the members of the preparation groups into different discussion groups minimized in addition to the free-rider problem. $17.65 \%$ of the students' statements in this category online $P B L$ setting highlighted the high interactivity in the online discussions and $23.53 \%$ stressed that 
they appreciated the increased flexibility and efficiency of the online setting. The online PBL setting had for the faculty the additional advantage that the second lecturer was able to contact students who have contributed little in a private chat during the plenary discussion. In this way, these students could be further motivated.

The last category built during the qualitative analysis was negative experiences (12.24\%). These students considered the course to be too time-consuming and highlighted as a problem difference in the ability to express themselves.

\section{Discussion}

The change from the face-to-face to the online setting affected mostly the reporting phase. The plenary discussion was planned in class and had to be switched to smaller discussion groups consisting of five to six students. This main change was highly appreciated by the students. This could indicate that the case discussions should be also in a face-to-face setting done in small discussion groups.

Students and faculty reported that the discussion in small groups resulted in a higher discussion quality. The setting increased the students' motivation. This is in line with An and Reigeluth (2008) who stated that if the online PBL sustains collaboration and interactive group discussion, an online PBL course can have a unique motivating effect. Hence, online settings can support PBL as they can facilitate personalized learning regardless of time and space boundaries, making learning more flexible and attractive (Şendağ \& Odabaşı, 2009). The increased flexibility but also the increased efficiency, since the discussion time was reduced in the online setting, were also stressed by some students. The flexibility as well as the possibility to contact students directly via private chat was highly appreciated by the faculty.

The results are indicating further that the main learning objective of a PBL course - integrating knowledge and promote the deep learning approach - can be achieved in an online setting. Students acquire a more in-depth understanding of the material and can reflect on the solution while gaining cognitive and independent-learning skills (McLellan, 2004; Dolmans, Loyens, Marcq, and Gijbels, 2016; Beattie, Collins, and Mcinnes, 1997; Furlong et al., 2003; Kahu, 2013). In addition, faculty reported that PBL can clearly foster problem-solving skills as well as critical thinking skills (Savin-Baden, 2007).

A further important point independently of the chosen instructional setting is the chosen cases. The practical orientation, as well as the variety, was appreciated by the students. Thus, it is not only important that cases present complex problems, which require intensive discussions, which facilitate the acquisition of higher cognitive skills (Şendağ \& Odabaşı, 2009), but also that the problems have a strong practical orientation.

The grading policy, which included a timely evaluation, did not provide detailed feedback on each grade. This was highlighted as a negative aspect by the students. However, a detailed timely assessment especially for the preparation assignment can be very challenging for the many lecturers involved given their time constraints. One idea could be to assess each rubric directly via Moodle instead of just communicating the final grade for the preparation assignment. For feedback on the plenary discussion grade, students should write a selfassessment of their contributions, which increases the ability for critical self-assessment. In addition, the weighting of the two parts (preparatory assignment and discussion) was questioned by the students and the faculty. Since the discussion is the more crucial part of PBL, faculty sees an optimal split as $40 \%$ versus $60 \%$. Thus, ensuring that the discussion is weighted more than the preparatory assignment. Otherwise, insufficient weight is given to students' independent learning and individual problem-solving and critical thinking skills, as well as to their ability to react in a discussion and to engage with others in an interactive situation. 
The role of the facilitator was not evaluated with the survey. Nevertheless, it can be assumed that the way of moderation influences the quality of the discussion.

\section{Conclusion}

The study contributes to PBL research by examining student and faculty experiences in a casebased PBL course. The results show that students enjoyed working with cases, as they covered a variety of topics and contained relevant and real-life problems. Students indicated that they would like to have more PBL courses in their degree programmes.

The shift from physical to online setting had no detectable negative impact on the ability of students to achieve set learning goals. The results show that students were able to apply knowledge and skills acquired in earlier semesters and were able to see how different business disciplines are connected. Furthermore, the results of the quantitative and qualitative evaluations show that the PBL course design promoted the acquisition of higher-level competencies such as the ability to analyse and evaluate knowledge, information, and situations (Savin-Baden, 2007). Critical-thinking, problem-solving and independent learning stayed at the centre of the course (Hmelo, 1998; Hmelo et al., 2000).

The change of the course from a physical setting required a change in course design, with most changes affecting the reporting phase. To maintain collaborative learning and interactivity the discussions no longer took place in large class settings, but rather in smaller groups of five to six students. This enabled a greater degree of individual contributions and enabled faculty to pick up on non-verbal cues from students (Yeo, 2005). Students also reported that smaller groups created a more collaborative and interactive environment, in which they were able to actively contribute to the discussions. Smaller group settings also proved to engage more "typically" shy students. Reporting phase in smaller settings also had a positive impact on the engagement of passive learners (Sugeng \& Suryani, 2020). Thus, increasing the individual motivation of students (McLellan, 2004; Dolmans et al., 2016). By mixing the teams, free-rider issues were also minimised (Lee et al., 2013). Since groups were now smaller, lecturers could also call upon students to contribute to the discussion, thus exposing those who failed to contribute to preparation assignment during the preparation phase. However, this needs to be investigated further.

Another important outcome is the availability and quality of feedback. Students expressed the need for timely and detailed feedback to be able to reflect and learn from mistakes. This poses a challenge, as a timely, and at the same time, a more detailed assessment can be a contradiction. However, faculty can explore additional mechanisms to promote self-reflection and independent learning, such as additional features of the LMS or by introducing peer-feedbacks or self-reflection reports (Liu et al., 2001).

In general, online PBL was well received by students as the approach increased flexibility $\mathrm{Ng}$ et al., 2014). It is crucial that the cases are well selected and present complex problems, which require intensive discussions, facilitating the acquisition of higher cognitive skills (Şendağ \& Odabaşı, 2009). This study has shown that an online PBL course can sustain collaboration and interactive group discussions as highlighted by An and Reigeluth (2008). In addition, online settings can support PBL as they can facilitate personalized learning regardless of time and space boundaries, making learning more flexible and attractive (Şendağ \& Odabaşı, 2009). In summary, the results show that an online PBL course can help students integrate knowledge and promote deep learning by strengthening students' critical thinking, problem-solving, independent learning, and team skills.

The results of the study are limited to this context and larger generalisations cannot be made due to the limited survey results. Further studies can look at the impact of feedback in a PBL 
setting consisting of an assessed preparation phase and reporting phase. Furthermore, analysing the differences in the two settings face-to-face and online with small discussion groups, thus keeping the number of students in the plenary discussion constant, could provide further insights into the strengths and weaknesses of the two settings. In general, the instructional concept of PBL should be further analysed and refined, as 6 of the top 10 skills for 2025 according to the future jobs report of the World Economic Forum (2020, p. 36) could be strengthened through problem-based learning.

\section{References}

An, Y. J., \& Reigeluth, C. M. (2008). Problem-based learning in online environments. Quarterly Review of Distance Education, 9(1), 1-16.

Barrows, H. S. (2000). Problem-based learning applied to medical education. Southern Illinois University Press.

Beattie, V. I., Collins, B., \& Mcinnes, B. (1997). Deep and surface learning: A simple or simplistic dichotomy? Accounting Education, 6(1), 1-12. https://doi.org/10.1080/096392897331587

Bocchi, J., Eastman, J. K., \& Swift, C. O. (2004). Retaining the online learner: Profile of students in an online MBA program and implications for teaching them. Journal of Education for Business, 79(4), $245-253$. https://doi.org/10.3200/JOEB.79.4.245-253

Chung, J. C., \& Chow, S. M. (2004). Promoting student learning through a student-centred problem-based learning subject curriculum. Innovations in Education and Teaching International, 41(2), 157-168. https://doi.org/10.1080/1470329042000208684

De Graaf, E., \& Kolmos, A. (2003). Characteristics of problem-based learning. International Journal of Engineering Education, 19(5), 657-662.

Dochy, F., Segers, M., van den Bossche, P., and Gijbels, D. (2003). Effects of problem-based learning: A metaanalysis. Learning and Instruction, 13(5), 533-568. https://doi:10.1016/s0959-4752(02)000257

Dolmans, D. H., Loyens, S. M., Marcq, H., \& Gijbels, D. (2016). Deep and surface learning in problem-based learning: A review of the literature. Advances in Health Sciences Education, 21(5), 1087-1112. https://doi:10.1007/s10459-015-9645-6

Donnelly, R. (2006). Blended problem-based learning for teacher education: Lessons learnt learning. Media and Technology, 31(2), 93-116. http://doi:10.1080/17439880600756621

Dykman, C. A., \& Davis, C. K. (2008). Online education forum: Part two-teaching online versus teaching conventionally. Journal of Information Systems Education, 19(2), 157-164.

Ertmer, P. A., \& Glazewski, K. D. (2019). Scaffolding in PBL environments: Structuring and problematizing relevant task features. In M. Moallem, W. Hug \& N. Dabbagh (Eds.), The Wiley Handbook of Problem Based Learning, (pp. 321-342). Wiley. https://doi.org/10.1002/9781119173243.ch14

Furlong, M. J., Whipple, A. D., Jean, G. S., Simental, J., Soliz, A., \& Punthuna, S. (2003). Multiple Contexts of School Engagement: Moving Toward a Unifying Framework for Educational Research and Practice. The California School Psychologist, 8, 99-113. https://doi.org/10.1007/BF03340899

Hill, J. R., Wiley, D., Nelson, L. M., \& Han, S. (2004). Exploring research on Internet-based learning: From infrastructure to interactions. Handbook of research on educational communications and technology. https://doi:10.4324/9781410609519-24

Hmelo, C. E. (1998). Problem-based learning: effects on theearly acquisition of cognitive skill in medicine. Journal of the Learning Sciences, 7(2), 173-208. https://doi:10.1207/s15327809jls0702_2

Hmelo, C. E., Holton, D. L., and Kolodner, J. L. (2000). Designing to learning about complex systems. Journal of the Learning Science, 9 (3), 247-298. https://doi.org/10.1207/S15327809JLS0903_2

Hmelo-Silver, C. E. (2004). Problem-based learning: What and how do students learn?. Educational psychology review, 16(3), 235-266. https://doi:10.1023/b:edpr.0000034022.16470.f3

Hung, W., Jonassen, D. H., \& Liu, R. (2008). Problem-based learning. In J. M. Spector, J. G. van Merrienboer, M. D., Merrill, \& M. Driscoll (Eds.), Handbook of Research on Educational Communications and Technology (pp. 485-506). Routledge.

Kahu, E. R. (2013). Framing student engagement in higher education. Studies in Higher Education, 38(5), 758773. https://doi.org/10.1080/03075079.2011.598505

Keeton, M. T. (2004). Best online instructional practices: Report of phase I of an ongoing study. Journal of Asynchronous Learning Networks, 8(2), 75-100. https://doi:10.24059/OLJ.V8I2.1829

Kirschner, P., \& Van Merriënboer, J. (2008). Ten steps to complex learning a new approach to instruction and instructional design. Routledge.

Kolmos, A., Du, X., Holgaard, J. E., \& Jensen, L. P. (2008). Facilitation in a PBL environment. UCPBL UNESCO Chair in Problem Based Learning. Aalborg University. https://vbn.aau.dk/en/publications/facilitation-in-apbl-environment 
Koschmann, T. D., Myers, A. C., Feltovich, P. J., and Barrows, H. S. (1994). Using technology to assist in realizing effective learning and instruction: A principled approach to the use of computers in collaborative learning. Journal of the Learning Science, 3(3), 225-262. https://doi:10.1207/s15327809jls0303_2

Lee, G. H., Lin, C. S., \& Lin, Y. H. (2013). How experienced tutors facilitate tutorial dynamics in PBL groups. Medical Teacher, 35(2), e935-e942.g.

Liu, E. Z., Lin, S. S., Chiu C., \& Yuan, S. (2001). Web-based peer review: The learner as both adapter and reviewer. IEEE Transactions on Education, 44(3), 246-251. https://doi.org/10.1109/13.940995

McLellan, H. (2004). The Case for Case-Based Teaching in Online Classes. Educational Technology, 44(4), 1418. http://www.jstor.org/stable/44428918

Ng, M. L., Bridges, S., Law, S. P., \& Whitehill, T. (2014). Designing, implementing and evaluating an online problem-based learning (PBL) environment-A pilot study. Clinical Linguistics \& Phonetics, 28(1-2), 117130. https://doi.org/10.3109/02699206.2013.807879

Norman, G. R., and Schmidt, H. G. (1992). The psychological basis of problem-based learning: a review of the evidence. Academic Medicine, 67(9), 557-565. https://doi:10.1097/00001888-199209000-00002

Prince, M. (2004). Does Active Learning Work? A Review of the Research. Journal of Engineering Education, 93(3). https://doi.org/10.1002/j.2168-9830.2004.tb00809.x

Reynolds, F. (1997). Studying psychology at degree level: Would problem-based learning enhance students' experiences?. Studies in Higher 263-275. https://doi.org/10.1080/03075079712331380886

Savin-Baden, M. (2007). A practical guide to problem-based learning online. Routledge.

Schmidt, H. G. and van der Molen, H. T. (2001). Self-reported competency ratings of graduates of a problembased medical curriculum. Academic Medicine, 76(5), 466-468. https://doi:10.1097/00001888-20010500000018

Schmidt, H. G., Vermeulen, L., and van der Molen, H. T. (2006). Long-term effects of problem-based learning: a comparison of competencies acquired by graduates of a problem-based and a conventional medical school. Medical Education, 40(6), 562-567. https://doi:10.1111/j.1365-2929.2006.02483.x

Şendağ, S., \& Odabaşı, H. F. (2009). Effects of an online problem-based learning course on content knowledge acquisition and critical thinking skills. Computers \& Education, 53(1), 132-141. https://doi:10.1016/j.compedu.2009.01.008

Smith, G. F. (2005). Problem-based learning: can it improve managerial thinking?. Journal of Management Education, 29(2), 357-378. https://doi:10.1177/1052562904269642

Sugeng, B., \& Suryani, A. W. (2020). Enhancing the learning performance of passive learners in a financial management class using problem-based learning. Journal of University Teaching \& Learning Practice, 17(1), 5. https://ro.uow.edu.au/jutlp/vol17/iss1/5

Wijnia, L., Loyens, S. M., \& Derous, E. (2011). Investigating effects of problem-based versus lecture-based learning environments on student motivation. Contemporary Educational Psychology, 36(2), 101-113. https://doi.org/10.1016/j.cedpsych.2010.11.003

World Economic Forum. (2020). The Future of Jobs Report 2020. Retrieved from http://www3.weforum.org/docs/WEF_Future_of_Jobs_2020.pdf

Yeo, R. (2005). Problem based learning: lessons for administrators, educators and learners. International Journal of Educational Management, 19(7), 541-551. https://doi: 10.1108/0951354051062558 